\title{
LIGHT AND LIFE IN THE SEA
}

A Symposium organised by the Marine Biological Association and held at the Polytechnic South West in Plymouth, 9-11 April, 1989

\section{Abstracts of Papers and Posters presented}

\section{PAPERS}

\section{Optical oceanography: an assessment of towed methods}

Aiken, J. \& Bellan, I. Plymouth Marine Laboratory, Prospect Place, The Hoe, Plymouth, PL1 3DH

Measurements of the optical properties of the oceans are assessed in the context of the requirements for the interpretation of satellite remotely-sensed images of ocean colour in terms of the biogenic constituents of the water, particularly dissolved compounds and phytoplankton pigments. Conventionally, optical measurements are obtained by profiling instruments vertically from a stationary research vessel, limiting the number of data acquired to a few per day, spread thinly over a small geographical area. In this paper, measurements of the optical properties of several large oceanic areas with diverse phytoplankton populations are presented, acquired by means of a suite of light sensors attached to the Undulating Oceanographic Recorder (UOR), towed at speeds of 4 to $6 \mathrm{~m}$ $\mathrm{s}^{-1}$ (typically $20 \mathrm{~km} \mathrm{~h}^{-1}$, covering $300-400 \mathrm{~km} \mathrm{~d}^{-1}$ ). The data acquired are compared with measurements by conventional instruments at stations and analysed for artefacts or bias in the towed measurements.

\section{Comparison of herring behaviour in the light and dark}

Blaxter, J.H.S. \& Batty, R.S. SMBA, Dunstaffnage Marine Research Laboratory, P.O. Box 3, Oban, Argyll, PA34 4AD

Herring have well-developed eyes and a complex acoustico-lateralis system. They require light to particle-feed, to school and to avoid stationary nets. Video techniques, using infra-red light invisible to the fish, show how they behave in low light intensities and in darkness. The schools disperse and activity drops but the fish retain an ability to filter-feed; they can also avoid vibrating obstacles.

Using larval herring of different age it is possible to observe behaviour when the sensory systems are at different stages of development. Using artificial sound and light, as well as predatory fish, as stimuli, it can be shown that dramatic increases in responsiveness occur when rods recruit to the retina and when the otic bulla and lateral line become functional. 


\section{Recent advances in photomorphogenesis and cell polarity using marine algal systems}

Brownlee, C. Marine Biological Association, The Laboratory, Citadel Hill, Plymouth, PL1 2PB

Responses to light play an essential role in the development of all photosynthetic multicellular plants. Plants can respond to light quality, irradiance, duration and direction. Two broad classes of response have been identified. These are phototropism in which the direction of cell growth or elongation is influenced by the light direction, and photomorphogenesis in which the patterns of cell differentiation and division respond to the incident light. The major pigments involved in these processes will be summarized. The special role of cell growth and polarity in plant morphogenesis is discussed. In zygotes of the Fucales, directional light can be considered to have both phototrophic and photomorphogenic effects, i.e. the light direction not only dictates the direction of growth of the emerging rhizoid, but influences the differentiation of the single cell zygote into distinct rhizoid and thallus cells. Evidence for the types of pigments involved in this response and their location plays a key role in translating a directional light signal to spatial information in the cytoplasm, which is ultimately transmitted to the genome. Progress has now been made in identifying the second messenger systems involved. Increase in our knowledge of how polarity is established and maintained at a molecular level in plant cells is leading to increased understanding of how a directional light signal is perceived and translated. A model is presented to describe the likely molecular mechanisms involved.

\section{Living light: from the ocean depths to the hospital bed}

\section{Campbell, A.K. Department of Medical Biochemistry, University of Wales College of Medicine, Heath Park, Cardiff, CF4 4XN}

Bioluminescent proteins and their luciferins can be detected down to $10^{-18}-10^{-21} \mathrm{~mol}$. This is sufficient to measure and locate intracellular signals such as $\mathrm{Ca}^{2+}$, energy supply in the form of ATP, and the end response of cells responding at their plasma membrane to activators, drugs or pathogens. Methods have been developed using liposome cell fusion, or transfection of cDNA or mRNA, to incorporate these bioluminescent indicators into living cells. This has led to the identification of two distinct mechanisms responsible for activating cells such as human neutrophils, one requires a rise in cytosolic $\mathrm{Ca}^{2+}$ the other does not. A mechanism of reversible cell injury induced by membrane pore forming proteins has also been discovered which appears to play an important role in inflammatory diseases such as rheumatoid arthritis and multiple sclerosis. The ability to clone and genetically manipulate bioluminescent proteins has led to their application as reporter genes and, at the patient's bedside, to their use as replacements for ${ }^{125} \mathrm{I}$ and ${ }^{32} \mathrm{P}$ in immunoassay and recombinant DNA technology. 


\section{Light and primary production in an atoll lagoon}

Charpy, Loïc \& Charpy-Roubaud, Claude Julia. ORSTOM, Centre Océanographique de Marseille, Rue de la Batterie des Lions, 13007 Marseille, France

The Tikehau atoll (French Polynesia) is located at $14^{\circ} \mathrm{S} 148^{\circ} \mathrm{W}$. Phytoplankton and sand microalgae are the most important primary producers of the lagoon.

Light effects on lagoon primary production were measured by using the ${ }^{14} \mathrm{C}$ method for phytoplankton and the $\mathrm{O}_{2}$ method for phytobenthos. All incubations were made in situ at different depth and light exposure times.

Light energy is high and 15\% of the surface light reaches the lagoon average depth ( 25 $\mathrm{m})$. Continuous $\mathrm{O}_{2}$ measurements in bell jars placed above the sediments show a very high correlation between light and $\mathrm{O}_{2}$ production without any photoinhibition. The phytoplankton assimilation number $\left(\mathrm{mg} \mathrm{C} \mathrm{mg}^{-1} \mathrm{Chl} a \mathrm{~h}^{-1}\right)$ is much higher between the surface and $2 \mathrm{~m}$ than at other depth levels.

The relative contributions of benthic and planktonic algae tend to be equal at depths between 10 and $15 \mathrm{~m}$.

\section{Gaia - Fact or Fancy?}

Craik, J.C.A. SMBA, Dunstaffnage Marine Research Laboratory, P.O. Box 3, Oban, Argyll, PA34 4AD

The Gaia hypothesis is entertaining and instructive but difficult to prove or disprove. Features of the biosphere are described which may provide alternative explanations of Gaian phenomena, or which are difficult to reconcile with Gaia. These arguments include consideration of the following: the communities of living organisms living in all extreme aquatic natural environments (of temperature, $\mathrm{pH}, \mathrm{pE}$, and salinity); the adaptability of life to successive environmental crises during biospheric evolution; and the remarkable properties of 'dissipative structures'.

\section{Polychromatic vision in mantis shrimp compound eyes}

Cronin, Thomas W. \& Marshall, N. Justin. University of Maryland, Baltimore County, Catonsville, Maryland, USA, and University of Sussex, Falmer, East Sussex

Structural evidence suggests that the retinae of stomatopod crustaceans (mantis shrimps) of the superfamilies Gonodactyloidea and Lysiosquilloidea include multiple spectral classes of photoreceptors. In some ommatidia, rhabdoms are tiered, and photostable coloured filters may be placed between the tiers. Such an arrangement could alter the spectral absorption in the various tiers, even if all tiers contained an identical visual pigment. We chose four mantis shrimp species for study, using end-on microspectrophotometry to identify the visual pigment of each tier in the main rhabdoms of various retinal regions in frozen sections of fresh material. As many as 10 visual pigments were found to exist in a single retina, having wavelengths of maximum absorption from 400$551 \mathrm{~nm}$. Because of the retinal tiering and the presence of the filters, at least 10 spectral classes of photoreceptors, each acting in a different spectral region, exist in the retina. All 
species we examined had similar distributions of both the visual pigments and the photoreceptor classes within their retinae. How these animals make use of the highly complex information supplied to them by their compound eyes, and the significance this may have for their survival, remain compelling questions for research.

\section{Light and vision at depths below $200 \mathrm{~m}$}

Denton, E.J. Marine Biological Association, The Laboratory, Citadel Hill, Plymouth, PL1 2PB

As daylight penetrates into the sea it is absorbed and scattered. Below about $200 \mathrm{~m}$ the residual daylight is blue, confined to a band around $\lambda=475 \mathrm{~nm}$. Its spectral distribution changes little with depth. The angular distribution of daylight is constant but its intensity falls about tenfold for every $70 \mathrm{~m}$ increase in depth. There are rapid and great changes of intensity at dusk and dawn.

Whilst daylight could be significant for vision down to almost $1000 \mathrm{~m}$, bioluminescent lights are important at all depths. These are mainly in the blue-green, but some animals emit light elsewhere, sometimes even in the far red. With distance the intensities of bioluminescent lights fall not only because of absorption and scattering but also as the inverse square law. The reflective properties of animals are evidently important.

The visual problems faced by deep-sea animals are discussed including those of detecting and recognizing prey and predators; catching prey; communication with their own species; holding depth stations in the daytime and self-camouflage. Special attention is devoted to the properties of lenses, visual pigments (photosensitive and stable), retinal organization and tapeta of fish and squid eyes.

\section{Bioluminescence: a major communication channel in the sea}

Herring, P.J. Institute of Oceanographic Sciences, Deacon Laboratory, Brook Road, Wormley, Godalming, Surrey, GU8 5UB

Communication in the broad sense includes a very wide range of interactions between species. Bioluminescent communication in the sea involves the emission of a light signal, its transmission through the seawater, and its visual reception by the target. The sender and receiver may be the same individual (for reflected luminescence) though in the most highly developed systems there are two participants, both of whom seek to maximize the efficient transfer of the information encoded in the signals. Features of the bioluminescence of different groups of marine organisms are considered in this context, and are related, where possible, to associated behavioural evidence for the selective value of the bioluminescent signals. 


\section{Molecular mechanisms of photosynthesis}

Hunter, C.N. Department of Molecular Biology and Biotechnology, University of Sheffield, Western Bank, Sheffield, S10 2TN

All photosynthetic organisms depend on a network of light-harvesting pigments (antenna) to transfer excitation energy to the reaction centre, where photochemistry occurs. Typically, there are several hundred pigments per reaction centre, each of which is held in a specific orientation by polypeptides. This arrangement optimises the rate and efficiency $(\sim 99 \%)$ of energy transfer. The increase of surface area for light absorption is often promoted by elaboration of the membrane housing these complexes into spherical, tubular or lamellar shapes.

The photosynthetic bacterium Rhodobacter sphaeroides is frequently used as a model system for molecular studies, owing to the relative ease with which genetic, biochemical and biophysical studies can be conducted. The antenna consists of $\alpha$ and $\beta$ polypeptides of around 50 residues, which aggregate to form $(\alpha \beta)_{6}$ or $(\alpha \beta)_{12}$ units. $\alpha$ and $\beta$ each bind bacteriochlorophyll and carotenoid absorbing at either 800,850 or $875 \mathrm{~nm}$ and $420-510$ $\mathrm{nm}$, respectively. Energy transfer between minimal units occurs in $10-20 \mathrm{ps}$; after $100 \mathrm{ps}$ the special pair of bacteriochlorophylls within the specialized reaction-centre complex become photo-oxidized. An electron is transferred to a bacteriophaeophytin acceptor within $4 \mathrm{ps}$, then to quinone $Q_{A}(200 \mathrm{ps})$, then $Q_{B}(100 \mu \mathrm{s})$. Subsequent electron and proton transfers result in energy stabilization and conservation by the cell.

\section{Does the response of picoplankton to light differ from that of other phytoplankton?}

Joint, I. Plymouth Marine Laboratory, Prospect Place, The Hoe, Plymouth, PL1 3DH

The occurrence of oceanic picoplankton was first described a decade ago when epifluorescence microscopy demonstrated the presence of small, unicellular cyanobacteria in oceanic, coastal and estuarine waters. As well as cyanobacteria, eukaryotic algae with cell diameters of $c a 1 \mu \mathrm{m}$ were also present in natural assemblages. Vertical distribution studies have suggested that cyanobacteria are more abundant at the base of the euphotic zone than in surface waters; recent work has suggested that the vertical distribution of eukaryotic picoplankton shows a biomass maximum below the cyanobacteria peak. Most cultures of cyanobacterial picoplankton appear to grow well only at irradiances of less than $50 \mu \mathrm{E} \mathrm{m}^{-2} \mathrm{~s}^{-1}$. Therefore, information from natural assemblages and culture conditions suggests that picoplankton are adapted to grow towards the base of the euphotic zone where irradiance is low.

This assumption of adaptation to growth at low irradiance is examined in detail. Data on vertical distributions of picoplankton from a variety of marine provinces demonstrate that cyanobacteria are as abundant in surface waters at high irradiance as in deeper water at the base of the euphotic zone. In addition, physiological measurements and photosynthetic characteristics do not demonstrate adaptation to growth at low irradiance in natural assemblages; fine structure studies of cyanobacterial thylakoids from natural assemblages also do not show any structural changes which would be compatible with 
growth at very low irradiances. There appears to be very little evidence to support the hypothesis that the response of picoplankton in natural assemblages to light is any different from that of other phytoplankton.

\section{Action spectrum of phototaxis in the zoospores of Pseudochorda sp. (Laminariales, Phaeophyceae)}

${ }^{*+}$ Kawai, Hiroshi, ${ }^{\dagger}$ Kubota, Mamoru, ${ }^{\dagger}$ Kondo, Takao, \& ${ }^{\ddagger}$ Watanabe, Masakatu. ${ }^{\dagger}$ Department of Botany, Faculty of Science, Hokkaido University. $\ddagger_{\text {National Institute }}$ for Basic Biology, Okazaki, Japan. *Present address: A G Müller, Fakultät für Biologie, Universität Konstanz, Postfach 5560, D-7750 Konstanz, FRG

Most of the swarmers of brown algae show obvious phototaxis, but there have been no reports on the precise measurements of the action-spectra. In the present paper, we report on the action-spectrum of phototaxis in zoospores of Pseudochorda sp. in culture and confirm that it is a blue-light response. These swarmers are recently reported to contain a flavin-like autofluorescent substance in the posterior flagellum, associated with the eyespot, and suggested to be involved in the photo-reception of phototaxis.

The experiment was carried out using a large spectrograph (National Institute for Basic Biology, Okazaki) and a cell-movement tracking system. The cubet containing swimming zoospores of Pseudochorda sp. was placed on the objective stage of the microscope. Then the unilateral monochromatic light of equal density from the xenon light source was irradiated on to the cubet. The traces of movement of individual zoospores (cells) before and after the irradiation were recorded by a video-camera and analyzed by an 8-bit computer system. The zoospores showed obvious positive phototaxis only between $360 \mathrm{~nm}$ and $480 \mathrm{~nm}$ with the maximum response occurring at $460 \mathrm{~nm}$.

\section{Optics of the eyes of marine animals}

Land, Michael. School of Biological Sciences, University of Sussex, Lewes Road, Brighton, BN1 9QG

The one type of eye that does not work under water is our own, where most refraction occurs at the curved air-cornea interface. Most marine animals with simple eyes make use of lenses instead, and the commonest design is the spherical 'Matthiessen lens' in which the refractive index decreases from centre to periphery. This has evolved at least six times. Alternatives are lenses with many components (some copepods), concave mirrors (some bivalves and ostracods), and in the unique and embarrassing case of Nautilus, a pinhole.

Several types of compound eye are found in marine animals, and the only one absent is the simple apposition type found in terrestrial insects, where the air-cornea interface of each facet produces the image. However, other apposition types that use inhomogeneous optics are common (Limulus, amphipods), and so are superposition eyes. In these eyes many facets contribute to the image at any one point, and they are of three kinds: 
those that use inhomogeneous (lens-cylinder) optics, those that use mirrors, and a recently discovered intermediate in crabs that uses a combination of a lens and a parabolic mirror.

\section{The chemistry of bioluminescence - origins and mechanisms}

McCapra, Frank. The School of Chemistry and Molecular Sciences, University of Sussex, Falmer, Brighton, BN1 9QJ

The structures of the luciferins so far discovered make chemiluminescent reactions very likely. The luciferases seem suited to relatively simple transformations such as removal of a proton. It is argued that these facts, together with the ease with which the probable biosynthesis of the luciferins is modelled by chemical reactions, point to a menu of inherently chemiluminescent reactions from which bioluminescent reactions are selected.

Light emission from bacteria is thought to be an accidental phenomenon accompanying a common redox reaction, and is merely an accompaniment to the main event. These observations predispose us to believe that in many ways bioluminescence is, or originated as, an accompaniment to other metabolic activities. It is to be hoped that the genetic techniques now being used to give DNA sequences for the luciferases will show how enzymes with functions other than the catalysis of bioluminescence became associated with small molecules with an inherent tendency to chemiluminesce.

\section{Messengers of transduction and adaptation in vertebrate photoreceptors}

Matthews, H.R. Physiological Laboratory, University of Cambridge, Downing Street, Cambridge, CB2 3EG

It is generally accepted that the processes of transduction and adaptation in vertebrate photoreceptors are mediated by diffusible internal messengers. Many lines of evidence, both biochemical and physiological, indicate that cyclic GMP is the messenger of transduction in both rods and cones. Cyclic GMP has been shown directly to open the channels in the outer segment membrane which carry the dark current. Light initiates an enzymatic cascade which culminates in the hydrolysis of cyclic GMP and the closure of these channels, to yield the photoresponse.

Changes in cytoplasmic calcium concentration are now known not to be directly involved in phototransduction, but instead play a fundamental role in light adaptation. Calcium concentration is believed to decrease in the light due to a shift in the balance between influx through the outer segment conductance and efflux through a sodiumcalcium exchanger. If this decrease is prevented then light adaptation is abolished, and both rods and cones saturate compressively at a relatively low intensity. Calcium is, therefore, the messenger of light adaptation in the photoreceptors of lower vertebrates. 


\section{The colour sensitivity and vision in fishes}

Partridge, J.C. Department of Zoology, The University, Woodlands Road, Bristol, BS8 3PS

The colour vision of fishes depends largely upon selective transmission of different wavelengths of light by the water in which they live. The clear waters of the open ocean are blue, the inshore waters off fertile land masses tend to be green, and fresh water is yellow green or brown. In very shallow water the underwater light is little different from that on land, and the fishes living there have the same spread of visual pigments as land animals. Fishes living at moderate depths in fresh water tend to have a large percentage of red-sensitive retinal cones, whereas those living in green coastal water have few red or even orange-sensitive cones. Deep-sea fishes live in an environment where light is very dim and predominantly blue in colour, whether from downwelling daylight or bioluminescence. Eighty-eight percent of deep-sea fishes have a single class of retinal rods which are maximally sensitive to this blue light, but $12 \%$ are rule-breakers and have two types of rod absorbing at different wavelengths. Fishes that migrate from one colour water to another, or from shallow to deeper depths are known to shift the visual pigments in their rods or cones in an apparent adaptation to the light climate in their new environment.

\section{Light and the capture of marine animals}

Pascoe, P.L. Plymouth Marine Laboratory, Citadel Hill, Plymouth, PL1 2PB

A wide variety of light-producing mechanisms and light-induced behavioural responses are utilized by marine animals both for prey attraction and predator avoidance. These responses have been exploited by man since prehistoric times with fishing techniques using light ranging in scale from simple to sophisticated and covering the marine environment from shore to deep ocean. The diverse applications of light in the capture of marine animals are reviewed. Experimental studies on the effect of artificial light on the efficiency and selectivity of various types of fishing gear are described and discussed.

\section{Physics of light in the sea}

Platt, T. \& Sathyendranath, S. Bedford Institute of Oceanography, P.O. Box 1006, Dartmouth, Nova Scotia, B2Y 4AZ, Canada

Life in the sea is ultimately linked to the quality and quantity of light available there. Primary production, upon which the entire trophic economy of the sea depends, is controlled by the spectral and angular distribution of underwater light. At the same time, the marine organisms themselves modify the submarine light field by absorption and scattering, and through the processes of fluorescence and bio-luminescence. The light produced underwater by marine organisms through fluorescence and bio-luminescence is a minute fraction of the sunlight reaching the sea surface, and is therefore safely neglected in most energy-budget calculations for the oceans. But it carries the spectral 
signature of the organisms that generate it, and thus has potential significance as a marker for them. Variations in the pigmented biota contribute to variations in ocean colour as seen by an observer outside the ocean, a phenomenon which is now being exploited for estimation, by remote sensing, of phytoplankton biomass and primary production.

The light field at the surface and in the interior of the oceans is described. Light emission within the sea by fluorescence and bio-luminescence is briefly discussed. We describe how the expected rate of photosynthesis depends on the characteristics of the submarine light field, and how this information can be used in remote sensing applications.

Our discussion is confined to the visible spectrum. Light penetration in water, marine photosynthesis, fluorescence by phytoplankton, and bio-luminescence all show strong wavelength-dependence, and it is therefore important to consider the spectral distribution, rather than just the total flux in the visible.

\section{Crepuscular behaviour of marine fish}

Potts, G.W. Marine Biological Association, The Laboratory, Citadel Hill, Plymouth, PL1 2PB

Direct observations on free ranging inshore fish indicate that most are either diurnally or nocturnally active. Hobson has shown that during these active periods behaviour is dominated by either feeding behaviour or by antipredator vigilance while at other times the fish are inactive. During the twilight period transitional behaviours are shown which change rapidly as the light levels change. Some predatory species are particularly active at these times and are truly crepuscular exploiting other species in their transitional behaviours. While most data are from tropical reefs there is evidence that similar behaviours are present in fish in shallow temperate seas.

There is a relationship between the fish size, the time it seeks shelter in the twilight period and its proximity to the sheltered situations.

\section{Remote sensing - information from the colour of the seas}

Robinson, I.S. Department of Oceanography, University of Southampton, University Road, Southampton, SO9 5NH

Remote sensing techniques from aircraft or satellite platforms are providing marine scientists with a new perspective of the oceans. This paper considers advances in methods which use visible wavelengths of light. The fundamentals of ocean colour imaging techniques are reviewed, and their sampling capabilities are compared with conventional methods of marine observation.

The approaches for extracting quantitative information from visible wavelength image datasets are discussed. The first uses ocean colour as a measure of the water content. This technique is reviewed, from its theoretical basis to the state-of-the-art algorithms which recover chlorophyll concentration. Examples are presented from the North Atlantic, and airborne measurements of Mesodynium rubrum in Southampton 
Water are described. Improvements in the technique should result from current optical experiments and from a new generation of satellite imaging spectrometers.

The second approach uses colour as a tracer of upper ocean dynamics. The patterns observed in ocean eddies contain information about dispersive processes; productive patches can be related to zones of vertical mixing; shelf-sea images reveal suspended sediment transport; flow velocities are measured from sequential satellite images. Conclusions are drawn about the importance of remote sensing to large scale oceanographic experiments.

\section{On the contribution of light to patchy distributions in the sea}

\section{Rodriguez-Mielgo, C. \& Pacheco-Castelao, J.M. Facultad de Ciencias del Mar, Universidad Politécnica de Canarias, Las Palmas, Spain}

Patchy distributions of biomass are of foremost importance in several areas of marine interest. Various attempts to model growth and extension of patches in the sea are known. Here we concentrate on estimates of patch size via a logistic-stochastic approach, where we introduce into the model the effect of large- and small-scale eddies. Recent research shows that some turbulence effects depend on light intensity and duration, so we model these effects by splitting our original model equation into two different ones of Langevin type. The resulting Fokker-Planck equation is studied and solved afterwards.

\section{The photic zone}

Tett, P. Marine Science Laboratories, Menai Bridge, Gwynedd, LL59 5EY (Paper read by P J LeB Williams)

The photic zone is the illuminated surface layer of the oceans wherein the absorption of heat energy by water and light energy by phytoplankton helps to regulate many aspects of the global environment. This review particularly considers the way in which optical conditions and vertical turbulent mixing determine the maximum depth to which microalgal populations can grow. The historical development of compensation and critical depth theory is reviewed and the theory re-examined to give the equations :

$$
\begin{aligned}
& \text { compensation depth }: \mathrm{zc}_{\mathrm{omp}}=\left(1 / \lambda_{\min }\right) \cdot \ln \left(\mathrm{m}_{2} \cdot \mathrm{I}_{\mathrm{o}} / \mathrm{I}\right) \\
\text { critical depth : } & \mathrm{zc}_{\mathrm{omp}}=\mathrm{f} \cdot \mathrm{m}_{2} \cdot \mathrm{I}_{\mathrm{o}} /\left(\mathrm{I}_{\mathrm{c}} \cdot \lambda_{\min }\right)
\end{aligned}
$$

where $\lambda_{\min }$ refers to the coefficient of attenuation of downwelling photosynthetically active radiation (PAR, as photon flux density) for the wavelength to which the sea is locally the most transparent; $\mathrm{m}_{2}$ is a correction for additional near-surface losses of polychromatic PAR; $f$ is a correction for the non-linear relationship between photosynthesis and irradiance; $I_{o}$ is 24 -hour sea-surface PAR; and $I_{c}$ is the compensation illumination, that at which 24-hour photosynthetic production of organic material is exactly balanced by its consumption. The compensation illumination is given by

$$
\text { Ic }=\alpha_{m} /\left(r^{\mathrm{B}}+\mathrm{l}^{\mathrm{B}}\right)
$$


where $\mathrm{r}^{\mathrm{B}}$ and $\mathrm{I}^{\mathrm{B}}$ are rates of chlorophyll-related loss of organic production by, respectively, algal respiration and other degradative processes, and $\alpha_{\mathrm{m}}$ gives the efficiency of photosynthesis at low illuminations. Its value may be synthesized from data on photosynthetic quantum yield, the photosynthetic quotient, and the absorption cross-section of the photosynthetic pigment complex. Factors affecting the compensation illumination for a range of algae and water types are discussed, and the effect of microheterotroph respiration is exemplified. The euphotic zone is defined as including all mixed layers in which photoautotrophic production exceeds heterotrophic consumption on the timescale under investigation. The lower limit to the zone is set sometimes by the compensation depth and sometimes by the critical depth. A conventional value of about $6 \mu \mathrm{E} \mathrm{m}$ ${ }^{2} \mathrm{~s}^{-1}$ for I leads to critical depth estimates compatible with the observed start of the spring phytoplankton increase in temperate seas, but much of the loss term implicit in this value must be due to losses other than algal respiration. A realistic minimum for $I_{c}$ is $0.3 \mu \mathrm{E} \mathrm{m}$ ${ }^{2} \mathrm{~s}^{-1}$ for diatoms in clear ocean water. For $\lambda_{\min }$ of $0.05 \mathrm{~m}^{-1}$ this predicts a compensation depth of about $120 \mathrm{~m}$, explaining the occurrence of deep chlorophyll maxima in the stratified oceans. Finally, it is suggested that it may have been mixing conditions in the oceans of the early Earth which forced primitive algae to develop mechanisms of the greatest possible efficiency.

\section{Light and the sublittoral ecology of temperate symbiotic anthozoa}

Turner, John R. School of Ocean Sciences, Marine Science Laboratories, Menai Bridge, Anglesey, Gwynedd, LL59 5EY

The role of submarine light in the ecology of temperate Anthozoa harbouring the algal symbiont Symbiodinium microadriaticum was investigated in Lough Hyne, Eire. Irradiance, more than substrate-type, water-movement, or food availability, limited the depth distribution of the symbiotic anemones Anemonia viridis and Anthopleura ballii to $-25 \mathrm{~m}$. In situ measurements of $\mathrm{E}_{\mathrm{d}}$ (PAR) characterized the sharp attenuation of irradiance with depth in the Lough $\left(K_{d}=0.17\right.$ to $\left.0.19 ; Z_{m}=-12 \mathrm{~m} ; Z_{\text {eu }}=-23 \mathrm{~m}\right)$. Anemonia was most

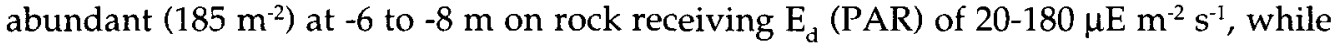
Anthopleura density on shell debris reached $39 \mathrm{~m}^{-2}$ at -13 to $-15 \mathrm{~m}$ at an $\mathrm{E}_{\mathrm{d}}$ (PAR) of 6-50 $\mu \mathrm{E} \mathrm{m}^{-2} \mathrm{~s}^{-1}$. Continuous in situ measurements of $\mathrm{E}_{\mathrm{d}}(\mathrm{PAR})$ in winter and summer recorded at $0 \mathrm{~m},-1.5 \mathrm{~m}$ and $-9 \mathrm{~m}$ were used to construct daily irradiance curves to which experimentally derived data of the symbiont photosynthesis characteristics were applied. It was inferred that total daily irradiance was insufficient for complete autotrophy at any depth in winter, and below $-9 \mathrm{~m}$ in summer. In situ behavioural observations demonstrated that symbiotic anemones optimized energy input by diurnal expansion and nocturnal collapse; responses that were direct rather than endogenous in control. The study illustrated that the nature of symbiosis alternated between parasitism in winter, and mutualism in summer, due to changes in seasonal submarine light. 


\title{
A reinterpretation of Kellogg \& Rice's results on visual problem solving in a bottlenose dolphin
}

\author{
Webb, N.G. 10 Swaffham Road, Reach, Cambridge, CB5 0HZ
}

In 1966, Kellogg and Rice trained a captive eight-year-old bottlenose dolphin, Tursiops truncatus (Montague) to discriminate between a variety of two-dimensional targets. The targets were then altered in order to test the dolphins' ability to stretch an association between targets of different shape. Previous workers claimed that no single rule or principle could have been transferred from learned pairs of two-dimensional visual targets to the corresponding test pairs, and that the problem was more complex than one of applying the same rule in multiple situations. In fact the dolphin succeeded on all occasions where one of the two stimuli was conserved under a rotation, and failed on all occasions where the test targets were not related to the original by a simple rotation. This is entirely predictable if the animal has developed the concept of the permanent object.

\section{Automated fluorescence detection of phytoplankton and bioluminescence-poten- tial in micro-organisms}

*Yentsch, C.M., *Yentsch, C.S. \& ${ }^{\dagger}$ Losee, J. *Bigelow Laboratory for Ocean Sciences, West Boothbay Harbor, Maine, USA 04575. ${ }^{+}$Naval Ocean Systems Center, San Diego, California, USA 925152

Sensitive photomultiplier tubes have permitted the development of such oceanographic tools as flow cytometers and bathyphotometers. With these optical instruments, measurement of fluorescence and bioluminescence, respectively, can be made on individual microorganisms.

We present here distribution data from a cruise to the Gulf of California in February and March 1988 where these instruments were run side by side. For flow cytometry, fluorescence from chlorophyll (excited at $488 \mathrm{~nm}$; emission greater than $675 \mathrm{~nm}$ ) was used as the discriminating characteristic for phytoplankton, and fluorescence from luciferin (excited at $488 \mathrm{~nm}$; emission window between 515 and $530 \mathrm{~nm}$ ) was used as the discriminating characteristic for bioluminescence potential.

Additionally a cytochemical stain, flourescein diacetate (FDA) was used to determine what percentage of the microorganisms were metabolically active. The direct bathyphotometer data represent surface mapping and depth distribution and were used for comparison. In some cases the fluorescence data and the bathyphotometer data compare well, though in other cases they do not.

These data challenge some basic assumptions. Observations using an epifluorescence microscope suggest that most of the single-cell bioluminescence was from Noctiluca sp. and other dinoflagellates, as well as radiolarians and silicoflagellates. 
POSTERS

\section{The relationship between in vivo chlorophyll fluorescence yield, ambient light and photosynthetic activity}

Aiken, J. Plymouth Marine Laboratory, Prospect Place, The Hoe, Plymouth, PL1 3DH

The in vivo fluorescence (IVF) yield of chlorophyll, remains a technique of widespread application and great utility for the estimation of phytoplankton biomass, even though the fluorescence yield per unit of chlorophyll is highly variable. In practical terms, the variability is manifest as an instability and large standard deviation of the calibration coefficients of fluorometers used for the measurement of phytoplankton populations from different oceanographic regimes and a large uncertainty in the estimate of chlorophyll concentrations. The variability of IVF yield has been examined in laboratory experiments and in situ measurements, and the degree of fluorescence quenching (the reduction of the IVF yield from an optimal value) has been found to be directly related to the intensity of the ambient light (or Photosynthetically Active Radiation, PAR). From the measurements, an accurate interpretation of the relationship between IVF and chlorophyll concentration can be derived and used to reduce greatly the uncertainty associated with the measurements hitherto. As quenching arises primarily from bioenergetic processes associated with photosystem II, an examination of the data in this context may provide an indirect measure of photosynthetic activity.

\section{Features on luminous cells in three marine copepods}

*Bannister, Neil J. \& ${ }^{\dagger}$ Herring, Peter J. *School of Animal Biology, University College of North Wales, Bangor, Gwynedd, North Wales, LL57 2UW. ${ }^{\dagger}$ Institute of Oceanographic Sciences, Deacon Laboratory, Wormley, Godalming, Surrey, GU8 5UB

The distribution and gross morphology of luminous cells, and associated cuticular pores, in three species of copepod, Metridia princeps, Euaugaptilus magnus and E. laticeps, is presented, along with a discussion on the morphological heterogeneity of secretory material in luminous cells of $E$. laticeps.

\section{Pholasin: a novel bioluminescent protein for measuring oxidative stress in single heart cells}

${ }^{*}$ Cotton, Beverley, ${ }^{*}$ Allshire, Ashley, ${ }^{*}$ Cobbold, Peter H., ${ }^{+}$Miller, Thomas \& ${ }^{+}$Campbell, Anthony K. *Department of Human Anatomy \& Cell Biology, University of Liverpool, Liverpool, L69 3BX. 'Department of Medical Biochemistry, The University of Wales College of Medicine, Heath Park, Cardiff, CF2 2XN

Pholasin, an acidic glycoprotein from the rock boring mollusc Pholas dactylus, luminesces in the presence of $\mathrm{O}_{2} ; \mathrm{H}_{2} \mathrm{O}_{2}$ and $\mathrm{OH}$ radicals. We have microinjected pholasin into single isolated rat cardiomyocytes to assess the cytoplasmic availability of $\mathrm{O}_{2} ; \mathrm{H}_{2} \mathrm{O}_{2}$ and $\mathrm{OH}^{-}$in cells subjected to oxidative stress e.g. extracellular $\mathrm{H}_{2} \mathrm{O}_{2}(1-100 \mu \mathrm{M})$ and a mitochondrial uncoupler. 
An extracellular concentration of $\mathrm{H}_{2} \mathrm{O}_{2}$, between 1 and $5 \mu \mathrm{M}$, elicits a transient burst of luminescence which discharges only a small proportion of the pholasin. Removal of $\mathrm{H}_{2} \mathrm{O}_{2}$ followed by readmission results in a second spike of luminescence. We suggest that this results from a Fenton reaction producing $\mathrm{OH}$ radicals in a finite quantity of ferrous ions in the cytosol which are presumably re-induced once $\mathrm{H}_{2} \mathrm{O}_{2}$ is removed.

Initial results obtained with the mitochondrial uncoupler carbonyl cyanide $\mathrm{m}$-chlorophenylhydrazone (CCCP) reveal that uncoupling the mitochondria impairs the cell's ability to resist oxidative stress imposed by an extracellular $\mathrm{H}_{2} \mathrm{O}_{2}$ concentration as low as $0 \cdot 1 \mu \mathrm{M}$.

\section{Stable carbon isotopes in organic matter from benthic macroalgae (Antarctica): evidence for light intensity effects}

*Fischer, G. \& ${ }^{+}$Wiencke, C. *FB5 Geowissenschaften, University of Bremen, Bibliothekstraße, 2800 Bremen, West Germany. ${ }^{\dagger}$ Alfred-Wegener-Institute for Polar and Marine Research, Columbußtraße, 2950 Bremerhaven, West Germany

Stable carbon isotope composition, $\mathrm{C} / \mathrm{N}$ and $\mathrm{H} / \mathrm{C}$-ratios were determined in 20 macroalgal species collected in Antarctica and in algae grown under controlled light and temperature conditions. The isotope ratios for the antarctic algae range from $-8 \%$ o to $34 \%$. Species living in greater depth with slow growth rates have much lighter values (about -30\%o) than the fast growing species in shallow waters (about $-10 \%$ ). First results from light experiments (photoperiod $15-19 \mathrm{~h} ; 0^{\circ} \mathrm{C}$ water temperature) indicate an overall trend towards more negative values with a decreasing photon fluence rate and consequently a decreasing photosynthetic rate. The $\delta^{13} \mathrm{C}$-value of a Desmarestia species (brown alga) was $-34.7 \%$ at $3 \mu \mathrm{mol} \mathrm{m} \mathrm{m}^{-2} \mathrm{~s}^{-1}$ and increased to $-14.3 \% \circ$ at $50 \mu \mathrm{mol} \mathrm{m}^{-2} \mathrm{~s}^{-1}$.

Experiments in the temperature range of $0^{\circ} \mathrm{C}$ to $25^{\circ} \mathrm{C}$ under light-saturated conditions do not show a general relationship between water temperature and carbon isotope ratios.

\section{Visually mediated behavioural avoidance of towed sampling devices by larval fish: how an understanding of the properties of light underwater may be used to increase sampling efficiency}

Glass, C.W. \& Wardle, C.S. DAFS Marine Laboratory, P.O. Box 101, Victoria Road, Aberdeen, AB9 8DB

There is evidence that, under certain circumstances, zooplankton may be able to avoid towed sampling devices. Such avoidance can adversely affect population estimates and this is specially true for the more active larval fish. Observations suggest that catch variability is linked to light level and that behavioural avoidance of towed samplers is mediated by the visual system. Direct observations of a towed sampler (Gulf III) viewed from the sample path, reveal that it presents a characteristic high contrast against its background which varies depending on the light level and underwater visibility. At the highest light levels the sampler presents the highest image contrast and this may allow the larvae to detect the sampler at sufficient distance to allow them to avoid capture. At low light levels the image contrast is reduced. Consequently the fish first see the sampler 
at shorter range with less chance of escape.

A series of practical observations of factors that control the image contrast of objects under water, was made and a number of novel nose-cone attachments was designed in order to make the sampler less visible. The aim was to decrease the visual stimulus and therefore shorten the reaction distance at high light intensities; this creates a situation where the stimulus is similar at both high and low light intensities. Direct observations by divers and a remote controlled towed underwater vehicle, allowed selection of the best design and practical measurements of the effects on visual range are presented. Videotape illustrating the optical principles and mode of operation in the field will be shown.

\section{Arctic benthic irradiance characteristics and the life history of the arctic kelp, Laminaria solidungula J. Ag.}

Hooper, R.G. Department of Biological Sciences, Portsmouth Polytechnic, The Marine Laboratory, Ferry Road, Hayling Island, PO11 ODG

The low diversity of arctic seaweed communities may be attributed, in part, to poor irradiance conditions. Low winter sunlight levels are further reduced by sea ice which often covers northern seas for many months. Laminaria solidungula is the most successful marine macrophyte of the arctic. Phenological study of its life history shows that this plant is optimally adapted to cope with extended periods of darkness. New blade growth occurs mostly during the darkest winter months, using stored photosynthate. This provides maximal photosynthetic area to receive limited adequate irradiance. Photosynthetic efficiency is also maintained by cuticular sloughing of fouling bacteria.

The short day conditions of late October trigger production of reproductive sori and the resumption of linear growth. The sorus, though mature by December, retains the zoospores until triggered by favourable light conditions. Resultant gametophytes can mature at a size as small as a single cell allowing new sporophytes to be produced within days of the new light season. Later gametophytes are larger and may overwinter before producing new sporophytes. Sporophytes take several years to reach reproductive size. Following years of inadequate benthic irradiance, usually due to lack of ice melt, these kelps become smaller and may fail to produce sporangia.

\section{Bioluminescent indicators for studying the chemistry of living cells}

Houston, W.A.J, Sala-Newby, G., Davies, E.V., Aston, P., Jenkins, T., Firth, S., Scolding, N.J., Morgan, B.P., Compston, D.A.S. \& Campbell, A.K. Departments of Medical Biochemistry and Medicine, University of Wales College of Medicine, Heath Park, Cardiff, CF4 4XN

The activation of eukaryotic cells, and their injury by the immune system, viruses and bacterial toxins, requires the generation of intracellular signals generated at the plasma membrane. A chemisymbiosis between these and energy supply leads to covalent modification and structural rearrangement of proteins which then generate a threshold end response in the cell. In order to define the molecular basis of these events we have 
developed bioluminescent indicators for intracellular $\mathrm{Ca}^{2+}$ (obelin), ATP (beetle luciferase) and $\mathrm{O}_{2}^{-}$(pholasin), including their formation within the cell from mRNA.

Membrane pore-forming agents such as the membrane attack complex of complement induce within a few seconds a rise in intracellular $\mathrm{Ca}^{2+}$ which activates cellular metabolism, events such as secretion, and a mechanism enabling the cell to protect itself from attack. Such reversible injury to neutrophils and oligodendrocytes appears to play a major role in the pathogenesis of rheumatoid arthritis and multiple sclerosis.

\section{Studies of available irradiance flux and phytoplankton absorption}

Jordan, M.B. Plymouth Marine Laboratory, Prospect Place, The Hoe, Plymouth, PL1 3DH

Photosynthetic primary production is dependent not only on the flux of Photosynthetically Active Radiation but also on the spectral quality of that flux and the rate of absorption of the radiance by that particular phytoplankton population. This poster shows the results from some experiments to determine the variability of these parameters in coastal and shelf waters and the resulting effect on calculations of the rate of conversion of solar energy to chemical energy by phytoplankton.

\section{Pholas dactylus and its bioluminescence}

Knight, Jan. The Laboratory, 18 Western College Road, Plymouth, PL4 7AG and Plymouth Polytechnic, Drake Circus, Plymouth, PL4 8AA

The bioluminescence of Pholas dactylus has intrigued man for centuries yet its function remains unknown. In the wild, $P$. dactylus, from deep within a rock, on occasion may excrete into the sea a cloud of glowing mucus which continues to glow for some time. Extracts of the light-emitting organs have been analysed using a novel method which incorporates high pressure gel filtration and series luminometry. Various light-emitting events can be followed once the added inhibitor, ascorbate, has been removed at the top of the column. At acidic $\mathrm{pH}$ certain proteins are resolved and sometimes nine lightemitting events can be identified, not all of which are associated with protein. At alkaline $\mathrm{pH}$, as in seawater, virtually no separation of proteins occurs and the light profile mirrors precisely the pattern of the proteins. All evidence to date supports the existence of only one light emitter, lucidalin, which may be associated at different times with different proteins and protein complexes. The lucidalin-containing fractions from the separation do not all respond in the same way, in terms of the luminescence produced, to chemical stimulation.

\section{Photomorphogenesis in the brown alga Tilopteris mertensii (Tilopteridales)}

Kuhlenkamp, Ralph. Biology Department, Memorial University of Newfoundland, St John's, Newfoundland, ALB 2X9, Canada

Experiments showing the influence of light on the development of the filamentous brown alga Tilopteris mertensii indicate considerable similarities to those using the more 
extensively studied Fucales, especially Fucus.

The relatively large egg (up to $50 \mu \mathrm{m}$ ) is polarized by the direction of incident light into a rhizoid and a filament pole. Subsequent germination produces a rhizoid on the shaded side of the egg and a filament on the opposite, illuminated side. Both react phototropically to the direction of light.

Several experiments have been conducted to elucidate the polarization of the egg cell and the following phototropic responses. Tilopteris is easy to culture and its rapid development makes it an ideal system for physiological studies.

\section{Light and phytoplankton in the oligotrophic waters of the south-west Pacific Ocean}

Lemasson, L. Centre ORSTOM, BP 5045, 34032 Montpellier, Cedex 10, France

When natural phytoplankton assemblages from oligotrophic waters (south-west Pacific Ocean) are incubated in vitro and / or in situ, a dark uptake of $\mathrm{CO}_{2}$ (corrected from zero time absorptions) is often observed. In addition uptake of $\mathrm{CO}_{2}$ continues when lightincubated samples are transferred to darkness. This dark uptake has been observed for a long time in this part of the Pacific Ocean. Nearly equal light and dark $\mathrm{CO}_{2}$ uptakes also often occur simultaneously.

It is difficult to explain these observations, but this dark uptake is perhaps linked with a bacterial chemolithotrophic activity. It is not possible yet to give a definite answer to this problem. Evaluation, by means of carbon-uptake experiments, must take into account this dark uptake in these oligotrophic waters.

The mean quantum yield $\left(\mathrm{P}_{\mathrm{B}} / \mathrm{I}\right)$ for the whole water column $(0-200 \mathrm{~m})$, and for the phytoplankton fraction included between 0.5 and $1.2 \mu \mathrm{m}$, is $3.14 \mathrm{mg} \mathrm{C} \mathrm{mg}^{-1} \mathrm{Chl} a \mathrm{E}^{-1}$; this value is higher than those found in this region for the $0.5-50 \mu \mathrm{m}$ assemblage by an order of magnitude.

\section{The structure and function of the mid-band in the eyes of stomatopod crustaceans}

Marshall, N. Justin, Land, M.F. \& Cronin, T.W. University of Sussex, Falmer, Brighton, Sussex, BN1 9QG and University of Maryland, Baltimore County, Catonsville, Maryland, USA

The compound eyes of mantis shrimps (stomatopods) are divided into three distinct regions; the dorsal and ventral hemispheres, and the mid-band. From structural evidence, it appears that the mid-band in two superfamilies of mantis shrimp is adapted for colour and polarization vision.

Four rows of ommatidia in the mid-band constitute a colour vision system. Using multiple photopigments, a tiered arrangement of photoreceptive microvilli and longpass filters, eight sharply tuned spectral sensitivities are achieved. The filters, found in two mid-band rows, consist of intensely coloured carotenoids, analogous to those found in the eyes of birds and reptiles. They are positioned between microvillar tiers and modify the spectrum of light they transmit. The structure of the remaining two rows of the mid-band suggests they are designed for analysis of polarized light using two 
separate arrays of orthogonal microvilli. The ommatidia in the hemispheres are in all respects much like those of other malacostraca.

Many ommatidia from both hemispheres and all those from the mid-band, view the same narrow strip in space. This visual area is swept through the environment by complex and largely independent eye movements. This allows for simultaneous, serial processing of spatial, spectral and polarization cues. Mantis shrimps live in well-lit, spectrally complex habitats such as tropical coral reefs and are themselves often marked with species-specific colours. The mid-band seems to be a unique adaptation for survival and communication in this varied environment.

\section{Retinal morphology during growth of demersal teleost fishes}

\section{Mas-Riera, Josep. Istituto de Ciencias del Mar, Passeig Nal s/n, 08003 Barcelona, Spain}

Retinal structure from demersal teleosts that inhabit different depths on the continental shelf and slope was examined by light microscopy using classical techniques. Eye and retinal characteristics are described. Photoreceptor features and densities, outer segment dimensions, rod-cone ratios and convergence ratios were measured from transverse sections for different life stages of each of the species studied. Differences in retinal morphology that appear during growth, from larval stages to adults, and among species are related to the depths of occurrence.

\section{Photosynthesis and chromatic adaptation in Solieria sp. (Rhodophyta - Gigartinales)}

${ }^{*}$ Perrone, C., ${ }^{*}$ Felicini, G.P. \& ${ }^{\dagger}$ Cecere, E. *Istituto di Botanica, Università di Bari, v. Amendola 175, 70126 Bari, Italy. 'Istituto Talassografico, C.N.R., v. Roma, 3-74100 Taranto, Italy

Solieria sp. was collected in Mar Piccolo in Taranto (Mediterranean Sea) from drifting beds ( $3 \mathrm{~m}$ deep, turbid coastal waters).

Apical segments, cultured for 50 days under various light spectra (blue, green and red) at low photon fluence rates $\left(18 \mu \mathrm{E} \mathrm{m}^{-2} \mathrm{~s}^{-1}\right)$ in $\mathrm{N}$-enriched medium, showed similar total pigment concentration, higher than both fresh plants and unfiltered light cultures, owing to adaptation to low irradiance. The lowest chlorophyll content was found in red light; the highest (about $45 \%$ more than in fresh plants) from green-light cultures.

Phycobilin-content was highest in green and blue light. Phycocyanin increase was the highest in every test (up to about $80 \%$ in green and blue light). The PE/PC ratio, remarkably lower than in fresh material, was more or less constant (4-5) in any condition, while $\mathrm{PE} / \mathrm{Chl} a$ and $\mathrm{PC} / \mathrm{Chl} a$ ratios varied considerably from one treatment to another, showing lowest values in green light and the highest in red, due to variations in chlorophyll content. The maximum photosynthetic rate occurred in green light with green-light-adapted cultures. The same was found at the experiment end. The red-light cultures also showed relatively high photosynthetic rates. Thus, an adaptation response to light spectral composition took place but not in accordance the Engelmann's theory. 


\section{Light-induced retinal damage in Nephrops norvegicus (L.)}

*Shelton, P.M.J., *Gaten, E. \& ${ }^{+}$Chapman, C.J. *Dept of Zoology, Leicester University, Leicester, LE1 7RH. ${ }^{+}$Marine Laboratory, Victoria Road, Aberdeen, AB9 8DB

The Nephrops norvegicus visual system is adapted for low photon fluence rates. The eyes are of the reflecting superposition type with a tapetum and large rhabdoms. At the centre of the eye the approximately circular eyeglow patch covers about 3,000 facets and may be up to $3.5 \mathrm{~mm}$ in diameter. The distal shielding pigment is non-migratory and the eye uses superposition optics in both the light- and dark-adapted states. Electrophysiologically measured retinula cell acceptance angles (in air) are similar for dark- and lightadapted eyes and for cells in the centre of the retina are in the order of $30^{\circ}$. Light and dark adaptation involves migration of the retinula cell proximal screening pigment. In the light-adapted eye, distal migration of the pigment obscures the tapetum. Exposure of the eye to the range of daytime photon fluence rates found at the sea surface causes irreversible breakdown of the retinula cells. For a given photon fluence rate, the amount of damage caused depends both on the state of light adaptation and depth-related differences in eye morphology and sensitivity. The photon fluence rate causing $25 \%$ damage is approximately $1 \log$ unit higher for animals from $18 \mathrm{~m}$ compared with those from $135 \mathrm{~m}$.

\section{Compound eye morphology, pigment migration and light-induced retinula cell damage in mesopelagic decapod crustaceans}

*Shelton, P.M.J., * Gaten, E. \& ${ }^{+}$Herring, P.J. * Dept of Zoology, Leicester University, Leicester LE1 7RH. 'Institute of Oceanographic Sciences, Brook Road, Wormley, Godalming, Surrey, GU8 5UB

Sergestes corniculum, Acanthephyra purpurea and Systellaspis debilis were subjected to various light regimes and examined by light microscopy. All have superposition eyes with distal and proximal screening pigments. In S. corniculum they are very dense and subject to photomechanical movements. They are much sparser in the other two species and here only the proximal pigment appears to move. S. corniculum has spindle-shaped main rhabdoms of square cross-section; the distal rhabdom is very small. A. purpurea has rhabdoms with complex cross-sectional profiles; the distal rhabdoms are relatively large. In $S$. debilis rhabdom shape varies; the dorsal rhabdoms are square in cross-section, the older ventral rhabdoms are cross-shaped in profile. The large tapetal cells in S. debilis and A. purpurea are not distributed evenly throughout the eye but are concentrated dorsally and ventrally. The tapetum was not well preserved in S. corniculum. Preliminary experiments with all species suggest that they are prone to irreversible light-induced retinula cell damage. In S. debilis $4 \mathrm{~h}$ at $5 \times 10^{-2} \mu \mathrm{mol} \mathrm{m}^{-2} \mathrm{~s}^{-1}$ (Wratten 45 filter, $475 \mathrm{~nm}$ maximum transmission) causes catastrophic breakdown of the main rhabdom but the distal rhabdom remains undamaged. 


\section{Photo-oxidation of dimethylsuphide, dimethylsuphoniumpropionate and other dialkylsulphides in seawater}

*Watts, Simon, Brimblecombe, Peter, \& 'Shooter, David. School of Environmental Sciences, University of East Anglia, Norwich, NR4 7TJ. *Present address: School of Chemistry, University of Leeds, Leeds, West Yorkshire, LS2 9TJ. Permanent address: Chemistry Department, University of Auckland, Private Bag, Auckland, New Zealand

Dimethylsulphide (DMS) undergoes photo-sensitized oxidation in seawater. Field experiments suggest much of the DMS naturally present in the upper $5 \mathrm{~m}$ of the North Sea can be photo-oxidized over a 1-2 day period. Laboratory experiments using methylene blue as a model photosensitizer suggest that other dialkylsuphides appear to be less readily photo-oxidized than DMS. Dimethylsulphoniopropionate (DMSP) does not appear to be photochemically degraded even with photosensitizers. Photo-oxidation of DMS in seawater occurs at wavelengths $<400 \mathrm{~nm}$, increases in rate with ionic strength (although exchanging $\mathrm{Mg}$ or $\mathrm{Ca}$ for Na makes little difference to the rate) and decreases with $\mathrm{pH}$. The absorption spectrum of DMS in the wavelength range $290-400 \mathrm{~nm}$ shows only weak absorption bands requiring photo-oxidation to proceed via photosensitization. Solar radiation at about $330 \mathrm{~nm}$ is most important in inducing DMS photooxidation. In intense sunlight marine DMS should have a residence time of a few hours with respect to photo-oxidation at the sea surface.

A model of incident solar radiation as a function of wavelength, ocean depth, dissolved organic matter etc. is applied to the oxidation of DMS. Model predictions are consistent with experimental results. 